\title{
A katábasis de Orfeu no Brasil, por Cacá Diegues
}

Igor Barbosa Cardoso ${ }^{1}$

DOI: http://dx.doi.org/10.25187/codex.v5i1.10173

\section{Resumo:}

O mito de Orfeu foi reelaborado diversas vezes pelo cinema brasileiro. Procura-se contrapor a katábasis produzida por Cacá Diegues à de Marcel Camus, com Orphée Noir (1958), em dois momentos, em A cidade grande (1966) e Orfeu (1999). Argumenta-se que o bandido social e o traficante de drogas são personagens centrais para a produção de distintas composições do inferno feitas por Diegues.

Palavras-chave: Cacá Diegues; recepção da cultura clássica; bandido social; traficante de drogas

\begin{abstract}
:
The Orpheus myth was reworded several times by the Brazilian cinema. The intention is to compare the katábasis produced by Carlos Diegues to Marcel Camus, with Orphée Noir (1958), in two moments, A cidade grande (1966) and Orfeu (1999). The social bandit and drug dealer are central characters to produce different compositions of hell made by Diegues.
\end{abstract}

Keywords: Cacá Diegues; classical reception; social bandit; drug dealer

\footnotetext{
${ }^{1}$ Doutorando em História pela UFMG (bolsista CAPES), na linha de pesquisa História e Culturas Políticas, possui graduação e mestrado na mesma instituição. Atualmente, pesquisa recepção da cultura clássica no período da ditadura militar brasileira, em especial as produções escritas e cinematográfica de Roberto Freire. Tem interesse em História Antiga, Literatura, Cinema e Direitos Humanos.
} 


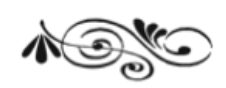

Cacá Diegues fez Orfeu descer ao Brasil algumas vezes ${ }^{2}$. Uma dessas descidas, de forma indireta, pode ser vista em seu filme de 1966, A grande cidade. Nele, a personagem de Anecy Rocha, a retirante Luzia, percorre a cidade do Rio de Janeiro em busca de seu noivo Jasão, interpretado por Leonardo Villar, que saíra sozinho das Alagoas em busca de um futuro melhor para o casal. Mas, tendo se transformado em um assassino profissional afamado nos jornais cariocas, Jasão havia se desacreditado dos sonhos planejados inicialmente, nos quais Luzia ainda mantinha fé. É ela então que descia ao inferno de Jasão e que, como uma luz na escuridão, procurava trazê-lo de volta ao mundo da utopia e dos projetos de transformação e ascensão social.

Nessa perspectiva, sugiro que $A$ grande cidade possa ser interpretada pela dupla tentativa de diferenciação: primeiramente, em relação ao mito de Orfeu, que, relido a partir da experiência brasileira, serviria de contraposição à estereotipada representação produzida por Marcel Camus em Orfeu Negro (1959); em segundo lugar, em relação à representação do bandido social, que, inserido no momento pós-golpe militar, qualificava historicamente esse inferno encenado no Rio de Janeiro.

Maria Cecília Coelho teceu importantes comentários acerca da presença do mito de Orfeu em $A$ grande cidade como contraponto ao filme de Camus por este apresentar uma brasilidade exótica, romântica e francófona ${ }^{3}$. No artigo, a autora demonstra quão cuidadosa foi a caracterização da cidade do Rio de Janeiro como cenário infernal da trama.

Já de início, como num prólogo, na baía de Guanabara, a personagem Calunga, encarnada por Antonio Pitanga, anuncia num tom farsesco que "essa terra é um paraíso terrestre", para, logo em seguida, direcionando-se ao espectador, com ar de quem prenuncia uma tragédia, perguntar como se já soubesse a resposta: “Quantas terras no mundo são um paraíso terrestre?”.

Com questionamentos que referenciam o mundo do trabalho, como "que horas o senhor acordou?", “quantas horas trabalha?", “o que o senhor faz no final de fim de semana?", "a que horas

\footnotetext{
${ }^{2}$ Erling B. Holtsmark (1991) apresentou alguns filmes que se inspiraram na katábasis, tema frequente na cultura antiga que se referia à descida do herói ao mundo subterrâneo, onde ele ganhava, após o retorno, alguma responsabilidade ou liderança com base nas suas experiências infernais. Como Holtsmark, não interessa aqui a representação moderna estritamente literal da descida ao inferno, mas o modo como alguns filmes colocaram em discussão certos padrões narrativos provenientes da Antiguidade Clássica.

3 Segundo Ivana Bentes, o filme de Camus "trabalha com uma miséria já transubstanciada em 'primitivismo', 'arcaísmo', simplicidade. A miséria não aparece no filme, os personagens vivem de forma 'primitiva', mas não de forma miserável. A miséria desaparece sob a capa de uma segunda natureza e de uma pobreza não-problemática" (BENTES, 2007, p. 247).
} 
vocês se amam?", feitas a transeuntes quaisquer, a personagem Calunga coloca em evidência as implicações materiais do existir, sem as quais seria impossível pensar até mesmo a produção do cinema nacional. Por isso, o questionamento diretamente feito aos espectadores, "o que é que estão fazendo no cinema?", solicita ao público que lide com o que o cinema é, "o templo de mágicas, a fábrica de sonhos, o antro da memória", segundo as palavras de Calunga.

Certamente, a passagem mais incisiva que ajuda a desenhar a cidade grande como espaço do inferno se dá quando Luzia, cansada do modo vulgar de Calunga, manda-o para o inferno e este lhe responde assim: “já estou nele, não está sentindo? Bota o cheiro pra dentro de você que até acostuma. Vira o que você pensar: perfume francês, cheiro de flor... respira, bota o inferno pra dentro de você". Sem ficar contrariada com os modos de Calunga, Luzia agora cede um sorriso, acenando positivamente ao convite de katábasis ao inferno.

É justamente por aprender a viver sem culpa, roubando e amando sem medida, que Calunga podia servir de guia a Luzia para transitar no inferno da cidade grande em busca de seu Jasão. O evidente contra-exemplo do malandro é visto em Inácio de Loyola, um retirante religioso e apaixonado por Luzia, que vive no passado com a esperança de retorno à terra natal que sempre se avizinha e nunca chega.

Vemos que, na roda de samba, onde tocam fortes tambores como se dessem início a um rito, Luzia encontra Jasão, denominado na cidade apenas por Vaqueiro, alcunha que demarca seu eterno lugar de estrangeiro, ainda que não se habituasse a essa posição. De todo modo, parece não ser ao acaso a escolha do nome Jasão, designação intimamente conectada ao mito de Orfeu, uma vez que as personagens participam em conjunto, na cultura clássica, da expedição da nau Argo, a fim de encontrar o Velocino de Ouro. Nela, enquanto Orfeu servia de guia espiritual devido a suas experiências infernais, Jasão era o reconhecido líder ${ }^{4}$. Já com o filme de Diegues, mesmo na condição de bandido poderoso e conhecido de toda a gente, Jasão se acovardava diante de Luzia, preferindo fugir de seus penetrantes olhares, sentindo-se envergonhado do que se tornara. Mais uma vez seria Calunga que serviria de meio para a aproximação entre os dois amantes.

É flagrante o desencontro entre o casal, observado por Luzia logo no primeiro encontro, visto que Jasão já não guardava qualquer imagem de santo na parede. Sua atividade na cidade, muito diferente da profissão almejada quando planejava sua saída do sertão, era a própria marca da

\footnotetext{
${ }^{4}$ Sobre a relação entre Orfeu e Jasão na cultura clássica, ver ROBBINS, 1982.
} 
descrença de um futuro melhor, figurada na manchete do jornal Última Hora: “Assaltante mata senador".

Vale a pena observar que o noticiário sobre o assassinato do senador vem acompanhado da reportagem sobre a instalação do segundo Ato Institucional, que propunha "novas cassações de mandatos", o fechamento do Congresso por dois meses, a elaboração de uma nova Constituinte, além do incentivo de "mais prisões". Para além de uma recusa individual às novas forças sociais que impõem um poder cuja autoridade é parcialmente sancionada pela sociedade, caracterização do bandido social segundo o conceito do historiador Eric Hobsbawm (1983; 2001), o distúrbio contra a ordem vigente representado no filme de Cacá Diegues é também o sintoma de um mal-estar insolúvel 5 .

Caso ouçamos o eco das palavras ditas por Calunga anteriormente, a saber, que o cinema é "o templo de mágicas, a fábrica de sonhos, o antro da memória", é possível que se apreenda que os sonhos de um Brasil revolucionário, frustrados após o golpe militar de 1964, ganhavam gradativamente o lugar do esquecimento. Contra um poder que se apoderava arbitrariamente da memória coletiva, o cinema fornecia os artifícios para a resistência possível. Mas Jasão representaria justamente o sonho vencido, envelhecido tão precocemente, desacreditado de Deus e de qualquer possibilidade de mudança.

Num dos momentos mais dramáticos do filme, em que Jasão revela a Luzia sua completa desesperança na grande cidade, o transtorno social, político e não menos psicológico é explicitado, fazendo evidenciar o próprio expectador, isto é, o povo, como o responsável pela produção do tempo infernal:

Primeiro foi só pra matar a fome, mas o sangue gruda na gente, cola na mão, no corpo, entra nos olhos e a gente se acostuma e o ódio se mistura com o amor. Eu odeio o povo porque ele pensa que não é culpado. Só a morte muda. Tomara que ela venha logo para mim, porque no inferno eu já estou.

\footnotetext{
${ }^{5}$ Ismail Xavier já observou, a partir da produção de Glauber Rocha, a proposta no Cinema Novo de uma "visão de passado e presente como contextos homogeneamente alienadores, focos estruturais de injustiça, diante dos quais a violência do oprimido ganha legitimidade como forma de resposta à violência institucional, muitas vezes invisível" (XAVIER, 2007, p. 149). É preciso ter em mente, portanto, que a figura do bandido social era socialmente compartilhada no Brasil, sendo largamente utilizada pelos artistas para responder a questões próprias do período.
} 
O bandido que mata o senador é o mesmo incapaz de agir para além do ato individual, pois não há projeto político de povo que sustente qualquer reação contrária ao estado implantado pelo golpe.

Como bem notou Maria Cecília Coelho, é extremamente relevante que o reencontro fatal entre Jasão e Luzia ao final do filme se dê na estação das barcas, no centro do Rio de Janeiro, mesmo local onde Eurídice (Marpessa Dawn), no filme Orfeu negro, chegava à cidade (o que geograficamente é inverossímil, pois ela teria de vir de Niterói). Mesmo sendo avisada por Inácio e Calunga de que os policiais, descobrindo o encontro amoroso marcado, usariam-na para descobrir o paradeiro de Jasão, Luzia parte para a estação das barcas na tentativa de salvá-lo, colocando-se, contudo, rumo ao inescapável final trágico de amor.

Contrariamente ao filme de Camus, o famoso olhar para trás do mito de Orfeu em Cacá Diegues remete não meramente ao melodrama do amor, mas ao passado ilusório, fantasmagórico, criado por intérpretes que romantizaram o povo brasileiro. Assim, se, por um lado, refutava-se radicalmente a ideia de um povo amistoso, fraterno e feliz, por outro, a denúncia de Diegues também falava de si, ao projetar a procura vã de um povo que não saiu às ruas para se proteger contra o golpe anti-revolucionário ${ }^{6}$.

Assim, a história de migração e amor, para qual o mito de Orfeu serviu de inspiração ao formular o ambiente infernal pelo qual o país passava, funda-se na frustração política e moral de um povo ainda não encontrado. No entanto, é preciso notar uma vez mais Calunga, personagem anárquica e amoral, qualificado pelos policiais que mataram Jasão e Luzia como quem "não vale nada". Por viver às margens da institucionalidade, do jogo político, Calunga sabia sobreviver no inferno, com seu jeito malandro, alegre e despojado.

\footnotetext{
${ }^{6}$ Como apontou Ivana Bentes (2007), a temática da favela levava cineastas brasileiros dos anos 1960 a duas questões centrais. Numa perspectiva ética, perguntavam-se pelo modo de representar a pobreza sem que se caísse no folclore, no paternalismo ou num humanismo conformista. Numa perspectiva estética, perguntavam-se pelo modo de levar o expectador a experimentar a radicalidade dos efeitos da pobreza. Segundo Marcelo Ridenti (2000), a resposta encontrada pelos cineastas ligados ao Cinema Novo não deixaria de perpetuar certo romantismo, entendido como retorno a um passado mítico, mas também não se confundiria com o romantismo autoritário encontrado nas posturas políticas leninistas ou fascistas.
} 
De certo modo, é possível associar na figura de Calunga certa remissão à sobrevivência marginal do orfismo contra a religião cívica no período clássico da Antiguidade ${ }^{7}$. Pois, para o ano de 1966, era como a um órfico que Calunga transitava na cidade grande, fazendo do inferno um paraíso possível para aqueles que se sabiam estrangeiros.

Há outras descidas de Orfeu produzidas pela lente de Cacá Diegues e algumas delas privilegiam a história de amor, como Veja esta canção (1994). Mas a segunda descida de Orfeu ao Brasil por Cacá Diegues, considerado o enfoque político e o contraponto mais direto ao que ele criticava no filme de Camus, deu-se 32 anos mais tarde. Em 1999, o filme Orfeu partia declaradamente da peça teatral de Vinícius de Moraes, Orfeu da Conceição, escrita em 1954, sobre a qual também Marcel Camus se inspirou para realizar seu filme Orfeu negro.

Temos em Orfeu, por um lado, a aproximação ainda mais explícita do mito órfico para refutar o argumento de Marcel Camus; por outro, ocorre um distanciamento entre os dois filmes de Diegues, caso levemos em conta as demandas do novo momento histórico. Gostaria de demonstrar que, se na década de 1960 o pária da sociedade foi construído na figura do malandro/marginal, já no final da década de 1990, a figura do traficante de drogas, o vagabundo, é quem tomava a cena e era capaz de aprofundar os conflitos no interior do morro ${ }^{8}$.

Lucinho, interpretado por Murilo Benício, é, portanto, uma das figuras centrais no enredo para que se caracterize o Morro da Carioca, onde quase toda a narrativa se desenvolve, incluindo o enlace de amor entre Orfeu (Toni Garrido) e Eurídice (Patrícia França), como espaço da violência difusa e periférica. Isto porque a violência perpetrada por Lucinho e seu bando não só atinge seu inimigo imediato e externo ao morro, a polícia, mas também toda a comunidade, que fica sujeita ou dependente ao poder exercido sem medidas. A meu ver, essa violência difusa e periférica caracteriza o ambiente infernal do morro.

Não é fortuito, por exemplo, que a primeira cena que Eurídice vê, ao chegar do Acre pela primeira vez ao Rio de Janeiro, no Morro da Carioca, no momento em que toda a comunidade se volta para os preparativos para o desfile de carnaval, seja a violenta entrada da polícia, que atira

\footnotetext{
${ }^{7}$ Ao pregar que deus está em todos os homens, contrariamente à concepção tradicional de que a apenas algumas figuras privilegiadas era dada a proximidade com os deuses, o orfismo se colocava como alternativa estranha "à cidade, às suas regras, aos seus valores" (VERNANT, 1992, p. 89). Por isso que a recusa pelo orfismo do sacrifício sangrento, ato ritual mais importante da religião política antiga, também servia de negação a certo tipo de comunicação entre os homens e os deuses (FESTUGIÈRE, 1988). Sobre a marginalidade do orfismo no período clássico e sua reverberação no período helenístico, cf. BRANDÃO, 1990.

${ }^{8}$ Sobre os conceitos de malandro, marginal e vagabundo, ver MISSE, 1999.
} 
como se ninguém transitasse ali. A resposta de um dos policiais, quando perguntado se aquele em que atirou não seria um "vagabundo", é reveladora: "não sei, mas se correu é porque deve estar devendo". Sob o signo do tráfico, todo o espaço da comunidade é condenado à morte.

Outra esfera de domínio mais sutil, mas também denunciada pela representação no filme, é o poder de consumo que Lucinho proporciona à comunidade. Quando o jovem Maykoll, nome significativo para indicar a produção de desejos por um mundo "hollywoodiano", defronta Orfeu em vista de um "tênis irado" visto na televisão, não há qualquer pudor em acrescentar que, caso ele, Orfeu, não lhe desse o que desejava, Lucinho não hesitaria em presenteá-lo, o que parece se concretizar numa cena mais à frente, quando Maykoll aparece com um novo tênis. A cena de dependência entre moradores e traficante se repete em outros momentos, inclusive após um brutal assassinato feito pelo bando.

O tiroteio entre traficantes e policiais é também motivo que leva uma família a se mudar do morro da Carioca. Nesse conflito, todos são convidados a tomarem distância. Num primeiro momento, por exemplo, Orfeu se coloca a favor do jovem Piaba a fim de protegê-lo da prisão, sem saber que ele estava recém ligado ao tráfico, o que lhe rende a repreensão do sargento Pacheco (Stepan Nercessian), ironicamente, padrinho de Lucinho. A intrigante e complexa relação que se desenvolve no morro, permeado de violência em todos os âmbitos, faz com que Eurídice perceba esse espaço como impossível para a realização plena de seu futuro e de sua felicidade. O drama chega ao limite quando ela decide ir embora do morro ao se perceber impotente para impedir o julgamento feito por Lucinho, que culmina no assassinato de um homem acusado de violência sexual.

É somente nesse limite, quando Eurídice ameaça romper definitivamente com qualquer possibilidade de relacionamento com Orfeu, que o enfrentamento entre dois caminhos possíveis, muito distintos, pode então ser radicalizado. Anteriormente a esse momento, quando Lucinho questionava por que Orfeu continuava a viver no morro, já que a fama de sambista permitir-lhe-ia condições de vida melhores em outro lugar, a resposta explicitava a tensão entre duas perspectivas de enxergar as dificuldades de viver na favela, elevada sob um enquadramento da câmera que procurava definir as escolhas díspares: "porque eu quero que todo mundo veja que pra se dar bem na vida não precisa ser igual a você”, dizia Orfeu a Lucinho. 
Dessa vez, Orfeu é quem dava o ultimato a Lucinho para que este fosse embora definitivamente do morro e todos pudessem desfrutar de um futuro menos tenebroso. A complexidade da trama, que apresenta a polícia corrupta e associada ao tráfico, não nos impede de afirmar que a representação infernal reside fundamentalmente na figura do traficante de drogas. É ele também, sem dúvida, a despeito do amor enciumado de Mira (Izabel Fillards), o elemento central que perturba a harmonia criada pelo amor entre Orfeu e Eurídice. Se em $A$ cidade grande, Luzia descia ao inferno de Jasão para tirá-lo do inferno, agora Eurídice é quem vai ao inferno de Orfeu para fazê-lo fundar um novo tempo que cesse o inferno imposto por Lucinho.

Orfeu tem a consciência do seu papel local e nacional na construção de outro imaginário do popular. Como lembra Ivana Bentes, ele tem "consciência que só é respeitado pela polícia e venerado pelo pessoal do morro porque tem mídia, sua arte é reconhecida fora dali. Orfeu é uma figura mítica e da mídia", que renasce junto a Eurídices, ao final do filme, pelas imagens da televisão (BENTES, 2007, p. 248).

Cacá Diegues não associa a figura do traficante de drogas ao próprio mal. Não existe sequer uma condenação veemente contra a personagem, visto que até mesmo se atribui uma perspectiva histórica que a humaniza, fazendo dela apenas uma engrenagem no moinho de moer gente do sistema capitalista. Lucinho é assim o trabalhador falho, aquele que não conseguiu ascender socialmente através de nenhuma habilidade que lhe permitisse não morrer como um desconhecido, feito o "otário" de seu pai, em seu próprio jargão. Tanto em Camus, quanto em Diegues, a estetização da pobreza sobe o morro do Rio de Janeiro; mas ao contrário de Camus, Diegues faz com que suas personagens saibam se apropriar da mídia e de seus recursos de sedução, espetáculo e performance para existirem socialmente.

Atento às mudanças de seu próprio tempo, Cacá Diegues soube representar dois infernos muito distintos e que procuraram se contrapor ao olhar mitificador sobre a favela brasileira representada por Marcel Camus. Embora distintos, os infernos de 1966 e de 1999 são produtos e produtores de uma cultura política de esquerda no Brasil, na qual se procurou, a cada momento, traduzir a tragédia de personagens periféricos na história do país ${ }^{9}$. Caberia avaliar, entretanto, o mito que se engendra com essas descidas ao inferno.

\footnotetext{
${ }^{9}$ Para o conceito de cultura política de esquerda, ver HERMETO, 2010.
} 


\section{Referências bibliográficas:}

BENTES, Ivana. "Sertões e favelas no cinema brasileiro contemporâneo: estética e cosmética da fome". Alceu, v. 8, n. 15, jul./dez. 2007, p. 242-255.

BRANDÃO, Jacyntho Lins. "O orfismo no mundo helenístico". In: CARVALHO, Sílvia Maria (org.). Orfeu, orfismo e viagens a mundos paralelos. São Paulo: UNESP, 1990.

COELHO, Maria Cecília. "Revendo A grande cidade, de Cacá Diegues: o orfismo às avessas da periferia”. HAMBURGER, Esther [et al.] (org.). Estudos de cinema Socine. São Paulo: Anablumme; Fapesp; Socine, 2008.

FESTUGIÈRE, André (et al.). Grécia e mito. Tradução Leonor Rocha Vieira. Lisboa: Gradiva, 1988.

HERMETO, Miriam. 'Olha a gota que falta': um evento no campo artístico-intelectual brasileiro (1975-1980). Belo Horizonte: UFMG, 2010. (Tese)

HOBSBAWM, Eric. Rebeldes primitivos: estudio sobre las formas arcaicas de los movimientos sociales en los siglos XIX y XX. Barcelona: Ariel, 1983.

. Bandidos. Barcelona: Crítica, 2001.

HOLTSMARK, Erling B. “The katabasis theme in modern cinema”. In: WINKLER, Martin (ed.). Classics and cinema. Lewisburg: Bucknell University Press, 1991.

MISSE, Michel. Malandros, marginais e vagabundos \& a acumulação social da violência no Rio de Janeiro. Rio de Janeiro: IUPERJ, 1999.

ROBBINS, Emmet. "Famous Orpheus". In: WARDEN, John (ed.). Orpheus: the metamorphoses of a myth. Toronto: University of Toronto Press, 1982.

RIDENTI, Marcelo. Em busca do povo brasileiro: artistas da revolução, do CPC à era da tv. Rio de Janeiro: Record, 2000.

VERNANT, Jean-Pierre. Mito e religião na Grécia antiga. Tradução Constança Marcondes Cesar. Campinas: Papirus, 1992.

XAVIER, Ismail. Sertão mar: Glauber Rocha e a estética da fome. São Paulo: Cosac Naify, 2007. 